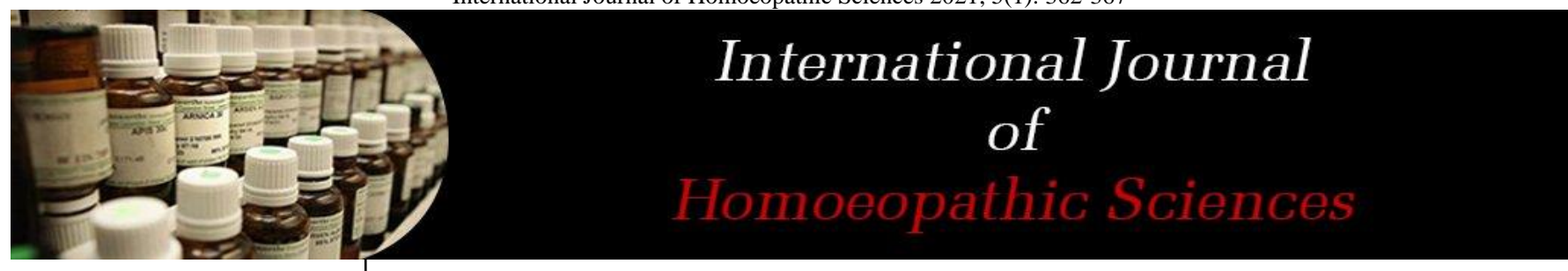

E-ISSN: $2616-4493$

P-ISSN: 2616-4485

www.homoeopathicjournal.com IJHS 2021; 5(1): 362-367

Received: 25-11-2020

Accepted: 27-12-2020

Dr. Kanak Kumar

Head of Department of

Practice of Medicine,

R.B.T.S., Govt. Homoeopathic Medical College and Hospital,

Muzaffarpur, Bihar, India
Corresponding Author: Dr. Kanak Kumar Head of Department of Practice of Medicine, R.B.T.S., Govt. Homoeopathic Medical College and Hospital, Muzaffarpur, Bihar, India

\section{Homoeopathich remedies in carcinoma}

\author{
Dr. Kanak Kumar
}

DOI: http://dx.doi.org/10.33545/26164485.2021.v5.i1f.340

\begin{abstract}
Homoeopathy is among the commonly used alternative approaches in Cancer. It is being widely used as palliative and curative in patients suffering from cancer. Though studies on the use of Homoeopathy in cancer after surgery, radio therapy and chemotherapy have been reported, clinical trials on effects of Homoeopathy in cancer are rare. Some studies on the effect of dosage of Homoeopathic medicines and their mechanism of action in cancer have also been published. A few case reports published here and there also find a mention in different databases. This review aims to describe literature available on the approach of Homoeopathy in Cancer by searching various databases from online library. It was found that beneficial effects of Homoeopathic medicine are reported on some cancer cell lines via apoptosis and immune modulation. Homoeopathic treatment given as add on also improves the quality of life, survival time and presenting complaints. However, more evidence needs to be generated to demonstrate anti tumor or antimetastatic potential in controlled clinical trials.
\end{abstract}

Keywords: alternatve system of medicine, cancer, homoeopathy

\section{Introduction}

Homoeopathy is among the most famous alternative system of medicine. In Europe, Homoeopathy is used in cancer care extensively from $6 \%$ in cancer diagnosis ${ }^{[1,2]}$ and almost $24 \%$ in breast cancer females ${ }^{[3,4]}$ Homoeopathy is most commonly used complementary and alternative medicine (CAM) in paediatric oncology in Germany and patient satisfaction with homoeopathic treatment is very high.[5] An overview of systematic reviews of CAM for cancer pain concluded that Homoeopathy might have a reduction in adult cancer pain ${ }^{[6]}$. Homoeopathy is a complete system of medicine which is established in practice and theory.

The basis of Homoeopathy is that:

- Similia similibus curentur (like cure like)

- Holistic treatment

- Serially diluted medicines prepared by succussion and dilution

- More a substance is diluted, more potent it becomes ${ }^{[7]}$.

According to the 2003 report of the World Health Organization, cancer is the 2nd largest cause of death in developed countries ${ }^{[8]}$ Conventional medicines are usually used to treat cancer. Side effects of non-surgical orthodox treatments limit their use despite they can treat and prevent cancer. In such cases, cancer patients turn towards alternative therapies including Homoeopathy ${ }^{[9]}$. In the UK, almost $30 \%$ patients in homoeopathic hospitals were referred directly by oncologists. However, a research program should need to setup for finding the efficacy of homoeopathic medicine against cancer. Some homeopathic medicines have been proven clinically and experimentally; however, there is a wide range of medicine on which data has not found ${ }^{[10]}$. Ernst ${ }^{[11]}$ and later Frenkel ${ }^{[12,13]}$ and Unlu ${ }^{[14]}$ described some data of homeopathy for cancer but not covered the whole topic. The present narrative review of homeopathic approach in cancer care was carried out to find researches reported in this field. The review comprises literature pertaining to the approach of Homeopathy in cancer using worldwide accepted scientific databases through electronic search.

\section{Approach of Homoeopathy in Different Types of Carcinomas}

In an animal model study, the inhibitory effects of potentised preparations of Hydrastis, Lycopodium, Ruta and Thuja against sarcomas that were induced by 3-Methylcholanthrene in mice as well as hepatocellular carcinoma induced by N'-nitrosodiethylamine in rats was 
studied. Biochemical, morphological and histopathological evaluation revealed that the reduction of elevated marker enzymes and tumour size. Among the four used medicines, Ruta 200c was most effective in reducing tumour size and incidence of sarcomas ${ }^{[15]}$. A homoeopathic medicine, Chelidonium in ultra-low doses showed antitumour and anti-genotoxic potential against hepatocarcinoma that was induced by azo-dye mice ${ }^{[16]}$. Condurango ethanolic extract and tincture showed antiproliferative action in lung cancer through apoptosis [17]. In another animal study. Anti tumor and anti metastatic effects of various homeopathic medicines were studied in mice against transplanted tumors. Hydrastis and Ruta significantly increased the lifetime of Dalton's Lymphoma Ascites and Ehrlich Ascites Carcinoma induced tumour -bearing mice. Moreover, these medicines showed marked reduction of solid tumour volume on the 31st day after tumour inoculation. Most of the Hydrastis 1M-treated animals were completely tumour free. Hydrastis 1M, Lycopodium $1 \mathrm{M}$ and Thuja $1 \mathrm{M}$ exhibited antimetastatic effect in B16F-10 melanoma-bearing animals. These medicines showed inhibition of lung tumour nodule formation and decreased levels of $\gamma-G T$ in serum ${ }^{[18]}$. Undifferentiated lung cancer, a woman with leiomyosarcoma and a child with an astrocytoma, were treated with a new homoeopathic approach of carcinogeninduced apoptosis ${ }^{[9]}$. A homoeopathic medicine, Sulphur, showed anti-apoptotic effect in non-small cell lung carcinoma cells ${ }^{[19]}$. Sabal serrulata mother tincture showed the reduction of prostate tumour xenograft size significantly in an in vivo trial. Moreover, Sabal serrulata decreased PC3 cell proliferation and DU-145 cell proliferation ${ }^{[20]}$. Permixon, a lipidosterolic extract of Sabal serrulata, is being used to treat symptoms of benign prostate hyperplasia $(\mathrm{BPH})$. It treats $\mathrm{BPH}$ by activating the permeability of transition pore of mitochondria, NF-KB apoptotic pathway and inhibition of 5- $\alpha$ reductase inflammatory-related gene. Insufficient research hinders to prove that Sabal serrulata is the right medicine for prostate cancer. Thuja along with Conium and Sabal serrulata in combination can assure more effective treatment against BPH [21]. In another research study, 220 patients of metastatic pancreatic cancer were administered by Viscum album sub-cutaneous 3 times weekly. Those who took this therapy needed no more anticancerous therapy. In those patients, brain metastasis was not observed. The patient receiving Viscum album as anticancerous remedy showed increase in the survival rate by 4.8 month and patients who took no treatment the survival rate was 2.7 month ${ }^{[22]}$. Pdimethylaminoazobenzene-induced hepatocarcinogenesis mice model which induce cytological changes such as chromosomal aberration mitotic activity and also chemical changes and reduced aspartate transaminase, lipid peroxidation, reduced glutathione carcinogenic changes was used to determine the anticarcinogenicity of Natrum sulph. These changes were reduced by Natrum sulphuricum. Natrum sulph 200 showed effective potential to reduce cancer as compared to Natrum sulph 30. ${ }^{[23]}$ Lycopodium clavatum 5C and $15 \mathrm{C}$ administration have any anticancer effects on human cervical cancer cell line HeLa cells by causing cell death through apoptosis in cancer cells. It induced DNA fragmentation, the increases in the expressions of protein, mRNA of caspase 3 and Bax and the decreases in the expressions of $\mathrm{Bcl} 2$ and Apaf and in the release of cytochrome-c. ${ }^{[24]}$

Anecdotal evidence showed the effectiveness of following medicines in different types of carcinomas ${ }^{[25]}$.

- Calcarea flour for breast cancer with hard and stony lumps

- Lapis albus for scirrhus and uterus malignancies with burning where oozing of fluid is black and putrid

- Silicea can be used as adjuvant to reduce cancer pain and also sarcoma with yellow and offensive discharge

- Hecla lava is a bone cancerous remedy

- Bryta carb for scattered lipomas

- Bryta iodium can cure ovarian cancer and mammae cancer with tuberculosis tinge

- Plumbum iodium in mastitis and induration of breast

- Bromine is a remedy for mammae cancer

- Phosphorus is used for cancer with bleeding tendency

- Iodium can be used for uterus cancers

- Cicuta virosa for epithelial cancer

- Kali sulph for facial epithelial cancer

- Cedron can be used to reduce the lancinating pains of cancer.

\section{Carcinogen-Induced Apoptosis, a New Homoeopathic Approach in Cancer}

A male with undifferentiated lung cancer, a woman with leiomyosarcoma and a child with an astrocytoma were treated with a new homoeopathic approach of carcinogeninduced apoptosis. Ultra-low doses of carcinogens were administered for 2-3 months and showed complete remission of cancer and increased life extension ${ }^{[9]}$.

\section{Palliative Approach of Homoeopathy in Cancer}

Homoeopathy can be used as a supportive or palliative treatment. As a palliative and supportive approach, homeopathy is used to develop general health and to relieve the pain and suffering resulting from other orthodox treatment ${ }^{[1,9]} \mathrm{A}$ case of metastatic adenocarcinoma of the rectum, terminal squamous cell carcinoma of the cheek and carcinoma of the larynx received received homeopathic medicines prescribed on constitutional grounds relieved the patient symptoms markedly. A male patient aged 64 years complains about bloody stool aggravated at night after eating and drinking. Distended abdomen with flatulence aggravated after eating and drinking and ameliorated after passing stool. Oedema of lower extremities since 2 years aggravated by sitting and standing. He has also history of inguinal hernia. Physical generals of patient were sweets desire, spicy food aversion and hurriedness. X-ray image showed $10 \mathrm{~cm}$ neoplasm at anal margin. Moderate differentiated adenocarcinoma with metastasis to liver and lymph nodes was diagnosed. Lycopodium 30c three times daily was prescribed for 4 days, Ruta-MT 5 drops for rectal bleeding. Rectal bleeding was better by flatulence, oedema and tenderness of iliac fossa. Stoppage of stool from 4 to 6 days was seen during follow-up. Lycopodium 30c was continued with un-medicated lactose three times a days about 1 month later, the patient come with these symptoms recurrent rectal bleeding, oedema and flatulence. Lycopodium 30c 2 times a day for 2 weeks was prescribed. The patient states remain stable for about $1 \frac{1}{2}$ month. Lycopodium was continued after every 3rd day. About 7 months later came with complaints of loose stool pain in the abdomen, left inguinal fossa with tenderness. Lycopodium in LM was prescribed. The case 
was followed up with Thuja and Lycopodium in 1 M potency. The patient came 5 months later with these symptoms rectal bleeding, no appetite, oedema and thirst for warm water. Arsenic 30c was prescribed ${ }^{[26]}$. Various research studies have been conducted to find the efficacy of homoeopathic medicines as a palliative therapy or to overcome adverse effects produced by other conventional treatments of cancer.

\section{Homoeopathic approach after radiotherapy}

A randomised controlled trial was conducted by Kulkarni to find the efficacy of Homoeopathy in decreasing the severity of radiotherapy-related adverse effects. Patients were grouped randomly divided into three groups. One group was given Causticum 30, a second group was given Cobaltum 30 and the third group received placebo. These medicines were selected on the basis of their use in decreasing symptoms of radiation reaction. Tumour reduction was insignificantly decreased in medicine groups ${ }^{[27]}$. In another study, effectiveness of homoeopathic medicines was investigated for radiotherapy-induced skin reactions in breast cancer patients. Patients were randomly divided in to two different groups. One group received homoeopathic treatment that consisted of X-ray $15 \mathrm{cH}$ and Belladonna $7 \mathrm{cH}$ while the other group received placebo. A topical medication containing fluocortolone was also administered to both groups. Cutaneous and subcutaneous oedema, erythema, hyperpigmentation and skin heat were primary outcome measures. Homoeopathic treatment showed a transient benefit regarding decreasing hyperpigmentation and skin heat, however, results became insignificant at the end of follow-up ${ }^{[28]}$. A study with 254 participants proved topical Calendula as powerful prophylactic as compared to trolamine in radiotherapy-induced dermatitis ${ }^{[29]}$.

\section{Homoeopathic approach after chemotherapy}

A preliminary, non-randomised controlled clinical trial tested the efficacy of Traumeel S on stomatitis occurred due to chemotherapy. Traumeel $S$ is a homoeopathic combination prepared by combining Calendula 2X, Millefolium 3X, Belladonna 2X, Arnica 2X, Hepar sulfuris $6 \times 0.1$, Symphytum 6X, Mercurius $6 \times 0.05 \mathrm{~g}$, Echiria purpura $2 \times 0.025 \mathrm{ml}$, Aconitum $2 \times 0.06$, Chamomilla $3 \mathrm{X}$, Bellis perennis $2 \times 0.05 \mathrm{ml}$ and Echinacea angustifolia $2 \mathrm{X}$. A total of 20 patients including children and teenagers received Traumeel $\mathrm{S}$ and were compared with seven controls (received no treatment for stomatitis) having similar stages of cancer and same age groups. The efficacy was determined by the pain level that was measured according to the requirement of opiates. Requirement of opiates and symptoms duration was significantly different in the intervention and control group favouring the treatment group ${ }^{[30]}$. Later, a larger randomised controlled trial (RCT) was carried out by same author to estimate the efficacy of Traumeel $S$ in cancer patients for stomatitis occurred due to chemotherapy after autologous or allogeneic stem-cell transplantation. During the first 7 days of trial, subjective symptom scores of patients were recorded. Intervention group showed significant reduction of duration and/or severity of stomatitis compared to control group ${ }^{[31]}$.

\section{Homoeopathic approach for menopausal symptoms after breast cancer}

A study was conducted to find the effectiveness of homoeopathic medicines on menopausal symptoms (mainly hot flushes) in breast cancer survivors. The patients included in the trial had a history of breast cancer in situ, Stage I-III, had completed breast cancer treatment either surgical, radiation or chemotherapy and had a history of at least 3 hot flushes/day for a month before study. All the patients were randomised in to three different groups: a verum single remedy and a verum combination medicine, a verum single remedy and a placebo combination and two placebo combinations. All patients were received individualised single homoeopathic medicines that can be one of these: Calcarea carbonica, Kali carbonicum, Lachesis, Sepia or Sulphur. The combination medicine was 'Hylands menopause', consisted of: Lachesis, Sanguinaria canadensis and Amyl nitrate. The efficacy was assessed regarding decreasing number and severity of hot flushes. Both Homoeopathy groups showed significant improvement in quality of life score compared to placebo. A subgroup of patients also received tamoxifen. There was significant increase in hot flushes in subgroup that had not received tamoxifen but received combination homoeopathic medicine compared to single remedy and placebo ${ }^{[32]}$.

A pilot study was carried out to find the effectiveness of Homoeopathy in breast cancer survivors having estrogen withdrawal clinical features. In this double-blind RCT, patients having more than three hot flushes per day, no coexisting treatment for hot flushes, not having metastatic disease, no severe contemporary disease; and not experiencing chemotherapy. All the patients were divided randomly in two groups to receive either homoeopathic medicines or placebo. Individualised homoeopathic medicines were prescribed to homoeopathic treatment group and the medicines mostly includes were Arnica, Belladonna, Carcinocin, Natrum muriaticum, Sepia and Sulphur. The efficacy was assessed by activity score (Primary outcome measures) and hot flushes frequency and severity (secondary outcome measures). No significant difference was observed between intervention and placebo group regarding both primary and secondary outcome measures at follow-up ${ }^{[33]}$.

\section{Different Studies Reporting Homeopathic Approach in Cancer}

In cross-sectional cohort study, two patient cohorts were compared; the characteristics of patients who were treated in a homoeopathic cancer care clinic and in a conventional oncology care clinic were compared. Their characteristics were different particularly the course of treatment after cancer diagnosis. Patients visiting homoeopathic cancer care clinic were mostly treated with either, chemotherapy, radiotherapy or the persons who refused to treat with conventional medicine. Moreover, mostly patients are young and employed so they have to earn their income during their cancer treatment. Hence, it is not justifiable to relate general plans when investigating conventional treatment with Homoeopathy ${ }^{[34]}$.

Retrospective data regarding survival time of cancer patients who take homoeopathic treatment complementary to conventional anticancer treatment showed extended survival time. The patients who had serious prognosis of disease receiving at least three homoeopathic consultations along with conventional cancer treatment were included in study and data regarding survival time and demographic characteristics of patients were collected in the University of 
Vienna ${ }^{[35]}$. However, a letter to editor said regarding the above study that the results biased and misleading because it is compulsory to apply a statistical model capable to handle the immortality time in control and active groups. KaplanMeier plots from literature should be used to establish control data ${ }^{[36]}$. Homoeopathic patient data were reanalysed by authors and comparison was done with control patient data from the same place. A probable immortal time bias has also been analysed in this re-analysis. Results of reanalysis showed statistically significant advantage of using Homoeopathy compared to control regarding survival time

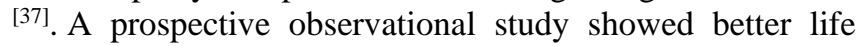
quality and decrease of fatigue in cancer patients who were treated with homoeopathic treatment compared to conventionally treated cancer patients. For comparison, both differently treated cohorts had comparable prognosis and same tumour entity. Adjunct classical homeopathic treatment improved subjective well-being and the global health status of cancer patients significantly in a pragmatic randomised controlled trial ${ }^{[38]}$.

A 5-year-old boy, suffering from bilateral strabismus, was computed tomography-scanned, which diagnosed a brain stem tumour. He was treated with combined conventional chemotherapy Temozolamide, Arsenic album 6X, Nitrated guanidine. Size of tumour was reduced from $6 \mathrm{~cm} \times 4 \mathrm{~cm}$ to $2 \mathrm{~cm} \times 2 \mathrm{~cm}$. ${ }^{[39]}$

Effects of Dosage of Homoeopathic Medicines on Cancer In an in vitro study, effects of homoeopathic medicines in low doses and high potencies in normal and cancerous human lymphocytes were studied. The methodology of study involved pretreatment of cells with either high potencies (pool 15-20c) or low concentrations (nM- $\mu \mathrm{M})$ of cadmium. After $120 \mathrm{~h}$ of medication, cells were exposed to cadmium $(8-80 \mu \mathrm{M})$.

MTS/PES assay was used to assess cell viability. For lower potencies, $\mathrm{NaCl} 0.9 \%$ and for high potencies water $15-20 \mathrm{c}$ was used as control. Both lower and higher potencies of cadmium pretreatment significantly increased cell viability in primary lymphocytes after toxic doses of cadmium compared to cells that have pretreatment of control. Low doses pretreatment effect was also significant in cancerous lymphocytes; however, high potencies showed no effect in cancerous lymphocytes ${ }^{[40]}$.

\section{Mechanism of Homoeopathic Medicines in Cancer}

An animal model study (mice) showed immunomodulatory effects of homoeopathic medicines in high dilutions having antineoplastic effects thus proposing their mechanism of action through immune modulation ${ }^{[41]}$. Sabal serrulata, Conium maculatum and Thuja occidentalis showed no direct cellular anticancer effects in an experimental animal study but slow the progression of cancer and decrease cancer occurrence and mortality significantly in induced prostate cancer in rats. [42] A study showed lack of immunomodulatory and apoptotic effects of Conium maculatum, Sabal serrulata, Thuja occidentalis in prostate cancer tissues of rats ${ }^{[43]}$. An in vitro study was conducted to find the effect of homoeopathic medicines on gene expression that controls apoptosis on breast and prostate cancer cells. Asterias, Conium maculatum, Carcinosin, Sabal serrulata, Thuja occidentalis and Phytolacca were tested; however, no medicine showed significant inhibitory or growth-promoting activity against breast or prostate cancer cells ${ }^{[44]}$. Another study also showed no significant change by the use of homoeopathic medicines in mRNA levels of the apoptotic genes, cytokines interleukin (IL)-1 $\alpha$, IL-1 $\beta$, caspase-1, 2 and 3, tumour necrosis factor and interferon- $\gamma$ in lung metastasis and prostate tumour. A nosode Carcinocin and a homoeopathic treatment regimen comprising Sabal serrulata, Conium maculatum and Thuja occidentalis were administered to observe effects on apoptotic genes [43]. However, in an in vitro model, Hydrastis canadensis 30c and Condurango 30c showing gene modulating effects compared to placebo (succussed alcohol 30c). A recognised epigenetic model was treated with above-mentioned homoeopathic potencies. Results of the study indicated that these homoeopathic dilutions acted through modulation of gene expression ${ }^{[45]}$. Chelidonium in ultra-low doses showed anti-genotoxic potential against hepatocarcinoma that was induced by azo-dye in mice [16]. An in vitro study showed apoptogenic effect of homoeopathic remedy, Sulphur, in non-small cell lung carcinoma cells ${ }^{[19]}$. Psorinum 6X was administered to various cell lines in vitro. It triggered apoptosis by inhibiting cell proliferation in A549 (human lung cancer cell line). Psorinum causes apoptosis through mitochondriamediated caspase-3-dependent pathway. Calf thymus-DNA was the target of Psorinum 6X as revealed on CD spectroscopy [46]. Rutin and quercetin are clastogenic and genotoxic. Ruta 6X with calcium phosphate induces signals of apoptosis in transplanted DLA cell and might be useful in glial cell lymphoma or intracranial cancer [47]. In Homoeopathy, Conium maculatum is being used traditionally for the treatment of cervix carcinoma and breast cancer. Its anticancer effect was studied in vitro in Hela cell. Conium caused accumulation of mucous membrane potential and reactive oxygen species and reduced colony formation and cell proliferation inhibiting sub-stage $\mathrm{G}$ of cell cycle. Phosphatidylserine cytochrome C and caspase 3 activation and inhibition of AKT and NFKB lead toward apoptosis and cell proliferation ${ }^{[48]}$.

\section{Conclusion}

Homoeopathy can be a useful approach in cancer. Various studies reported the effects of homoeopathic medicines in the management of cancer pain and other symptoms related to cancer. A few studies also tried to elaborate the mechanism of homoeopathic medicines in cancer using cellular and animal models. Some studies reported that apoptotic effects and modulation of gene expression of homoeopathic medicines in cancer while other studies negate this mechanism. In clinical arena, research studies of Homoeopathy in cancer are lacking and only described extended survival time in cancer patient or as an adjuvant with conventional treatment or removed side effects of conventional treatment. More evidence needs to be generated to demonstrate antitumour or antimetastatic potential in controlled clinical trial.

\section{References}

1. Molassiotis A, Fernadez-Ortega P, Pud D, Ozden G, Scott JA, Panteli V et al. Use of complementary and alternative medicine in cancer patients: A European survey. Ann Oncol 2005;16:655-63.

2. Lafferty WE, Tyree PT, Devlin SM, Andersen MR, Diehr PK. Complementary and alternative medicine provider use and expenditures by cancer treatment 
phase. Am J Manag Care 2008;14:326-34.

3. van der Weg F, Streuli RA. Use of alternative medicine by patients with cancer in a rural area of Switzerland. Swiss Med Wkly 2003;133:233-40.

4. Molassiotis A, Scott JA, Kearney N, Pud D, Magri M, Selvekerova $\mathrm{S}$, et al. Complementary and alternative medicine use in breast cancer patients in Europe. Support Care Cancer 2006;14:260-7.

5. Längler A, Spix C, Edelhäuser F, Kameda G, Kaatsch $\mathrm{P}$, Seifert $\mathrm{G}$, et al. Use of homeopathy in pediatric oncology in Germany. Evid Based Complement Alternat Med 2011;2011:867151.

6. Bao Y, Kong X, Yang L, Liu R, Shi Z, Li W et al. Complementary and alternative medicine for cancer pain: An overview of systematic reviews. J Evid Based Complementary Altern Med 2014;2014:1-9.

7. Paterson IC. Homeopathy: What is it and is it of value in the care of patients with cancer? Clin Oncol (R Coll Radiol) 2002;14:250-3.

8. Milazzo S, Russell N, Ernst E. Efficacy of homeopathic therapy in cancer treatment. Eur J Cancer 2006;42:2829.

9. Montfort H. A new homeopathic approach to neoplastic diseases: From cell destruction to carcinogen-induced apoptosis. Br Homeopath J 2000;89:78-83.

10. Thompson EA, Reillly D. The homeopathic approach to symptom control in the cancer patient: A prospective observational study. Palliat Med 2002;16:227-33.

11. Ernst E. Homeopathy for cancer. Adi Bsabs, Rami Srres, Reddy E. An open clinical study on the efficacy of Withania somnifera mother tincture in the management of hyperlipidemia. International Journal of Indigenous Herbs and Drugs 2019, P1-6. Curr Oncol 2007; 14:128-30.

12. Frenkel M. Homeopathy in cancer care. Altern Ther Health Med 2010;16:12-6.

13. Frenkel M. Is there a role for homeopathy in cancer care? Questions and challenges. Curr Oncol Rep 2015; $17: 43$.

14. Unlu A, Kirca O, Ozdogan M. Homeopathy and cancer. J Oncol Sci 2017;3:77-80.

15. Kumar KB, Sunila ES, Kuttan G, Preethi KC, Venugopal CN, Kuttan $\mathrm{R}$, et al. Inhibition of chemically induced carcinogenesis by drugs used in homeopathic medicine. Asian Pac J Cancer Prev 2007;8:98-102.

16. Biswas SJ, Khuda-Bukhsh AR. Effect of a homeopathic drug, Chelidonium, in amelioration of p-DAB induced hepatocarcinogenesis in mice. BMC Complement Altern Med 2002;2:4.

17. Sikdar S, Mukherjee A, Boujedaini N, Khuda-Bukhsh AR. Ethanolic extract of Condurango (Marsdenia condurango) used in traditional systems of medicine including homeopathy against cancer can induce DNA damage and apoptosis in non small lung cancer cells, A549 and H522, in vitro. Tang Humanitas Med 2013;3:e9:1-10.

18. Es S, Kuttan G, Kc P, Kuttan R. Effect of homeopathic medicines on transplanted tumors in mice. Asian Pac J Cancer Prev 2007;8:390-4.

19. Saha S, Bhattacharjee P, Guha D, Kajal K, Khan P, Chakraborty S, et al. Sulphur alters NFאB-p300 crosstalk in favour of p53-p300 to induce apoptosis in nonsmall cell lung carcinoma. Int J Oncol 2015;47:573-82.
20. MacLaughlin BW, Gutsmuths B, Pretner E, Jonas WB, Ives J, Kulawardane DV et al. Effects of homeopathic preparations on human prostate cancer growth in cellular and animal models. Integr Cancer Ther 2006;5:362-72.

21. Julià M, Vila Calsina E. The homeopathic effects of Sabal serrulata against prostate cancer. Autonomous University of Barcelona 2014;2:3.

22. Glickman-Simon R, Pettit J. Viscum album (mistletoe) for pancreatic cancer, electromagnetic field therapy for osteoarthritis, homeopathy for multidrug-resistant tuberculosis, Vitamin D for depression, acupuncture for insomnia. Explore (NY) 2015;11:231-5.

23. Bhattacharjee $\mathrm{N}$, Pathak S, Khuda-Bukhsh AR. Amelioration of carcinogen-induced toxicity in mice by administration of a potentized homeopathic drug, natrum sulphuricum 200. Evid Based Complement Alternat Med 2009;6:65-75.

24. Samadder A, Das S, Das J, Paul A, Boujedaini N, Khuda-Bukhsh AR, et al. The potentized homeopathic drug, Lycopodium clavatum (5C and 15C) has anticancer effect on hela cells in vitro. J Acupunct Meridian Stud 2013;6:180-7.

25. Boericke W. Pocket Manual of Homoeopathic Materia Medica \& Repertory: Comprising of the Characteristic and Guiding Symptoms of All Remedies (Clinical and Pahtogenetic [sic]) Including Indian Drugs. India: B. Jain Publishers 2002.

26. Rajendran ES. Homeopathy as a supportive therapy in cancer. Homeopathy 2004;93:99-102.

27. Kulkarni A. Radiation protection by use of homoeopathic medicines. Hahnemannian Homoeopathic Sandesh 1988;12:20-3.

28. Balzarini A, Felisi E, Martini A, De Conno F. Efficacy of homeopathic treatment of skin reactions during radiotherapy for breast cancer: A randomised, doubleblind clinical trial. Br Homeopath J 2000;89:8-12.

29. Pommier P, Gomez F, Sunyach MP, D'Hombres A, Carrie C, Montbarbon X, et al. Phase III randomized trial of Calendula officinalis compared with trolamine for the prevention of acute dermatitis during irradiation for breast cancer. J Clin Oncol 2004;22:1447-53.

30. Oberbaum M. Experimental treatment of chemotherapy-induced stomatitis using a homeopathic complex preparation: A preliminary study. Biomed Ther 1998;16:261-5.

31. Oberbaum M, Yaniv I, Ben-Gal Y, Stein J, Ben-Zvi N, Freedman LS, et al. Arandomized, controlled clinical trial of the homeopathic medication TRAUMEEL $S$ in the treatment of chemotherapy-induced stomatitis in children undergoing stem cell transplantation. Cancer 2001;92:684-90.

32. Jacobs J, Herman P, Heron K, Olsen S, Vaughters L. Homeopathy for menopausal symptoms in breast cancer survivors: A preliminary randomized controlled trial. J Altern Complement Med 2005;11:21-7.

33. Thompson EA, Montgomery A, Douglas D, Reilly D. A pilot, randomized, double-blinded, placebo-controlled trial of individualized homeopathy for symptoms of estrogen withdrawal in breast-cancer survivors. J Altern Complement Med 2005;11:13-20.

34. Guethlin C, Walach H, Naumann J, Bartsch HH, Rostock M. Characteristics of cancer patients using homeopathy compared with those in conventional care: 
A cross-sectional study. Ann Oncol 2010;21:1094-9.

35. Gaertner K, Müllner M, Friehs H, Schuster E, Marosi C, Muchitsch I, et al. Additive homeopathy in cancer patients: Retrospective survival data from a homeopathic outpatient unit at the medical university of Vienna. Complement Ther Med 2014;22:320-32.

36. Aust N. Prolonged lifetime by adjunct homeopathy in cancer patients - A case of immortal time bias. Complement Ther Med 2016;24:80.

37. Gleiss A, Frass M, Gaertner K. Re-analysis of survival data of cancer patients utilizing additive homeopathy. Complement Ther Med 2016;27:65-7.

38. Frass M, Friehs H, Thallinger C, Sohal NK, Marosi C, Muchitsch I, et al. Influence of adjunctive classical homeopathy on global health status and subjective wellbeing in cancer patients - A pragmatic randomized controlled trial. Complement Ther Med 2015;23:30917.

39. Rostock M, Naumann J, Guethlin C, Guenther L, Bartsch HH, Walach $\mathrm{H}$, et al. Classical homeopathy in the treatment of cancer patients - A prospective observational study of two independent cohorts. BMC Cancer 2011;11:19.

40. Wälchli C, Baumgartner S, Bastide M. Effect of low doses and high homeopathic potencies in normal and cancerous human lymphocytes: Anin vitro isopathic study. J Altern Complement Med 2006;12:421-7.

41. Remya V, Kuttan G. Homeopathic remedies with antineoplastic properties have immunomodulatory effects in experimental animals. Homeopathy 2015;104:211-9.

42. Jonas WB, Gaddipati JP, Rajeshkumar NV, Sharma A, Thangapazham RL, Warren J, et al. Can homeopathic treatment slow prostate cancer growth? Integr Cancer Ther 2006;5:343-9.

43. Thangapazham RL, Rajeshkumar NV, Sharma A, Warren J, Singh AK, Ives JA et al. Effect of homeopathic treatment on gene expression in Copenhagen rat tumor tissues. Integr Cancer Ther 2006;5:350-5.

44. Thangapazham RL, Gaddipati JP, Rajeshkumar NV, Sharma A, Singh AK, Ives JA, et al. Homeopathic medicines do not alter growth and gene expression in prostate and breast cancer cells in vitro. Integr Cancer Ther 2006;5:356-61.

45. Khuda-Bukhsh AR, Saha SK, Roy S. Evidence in support of gene regulatory hypothesis: Gene expression profiling manifests homeopathy effect as more than placebo. Int J High Dilution Res 2013;12:162-7.

46. Mondal J, Samadder A, Khuda-Bukhsh AR. Psorinum 6 $\times$ triggers apoptosis signals in human lung cancer cells. J Integr Med 2016;14:143-53.

47. Preethi KC, Nair CK, Kuttan R. Clastogenic potential of Ruta graveolens extract and a homeopathic preparation in mouse bone marrow cells. Asian Pac J Cancer Prev 2008;9:763-9.

48. Mondal J, Panigrahi AK, Khuda-Bukhsh AR. Anticancer potential of Conium maculatum extract against cancer cells in vitro: Drug-DNA interaction and its ability to induce apoptosis through ROS generation. Pharmacogn Mag 2014;10:S524-33. 